\title{
ДИНАМИКА ФИЗИЧЕСКОГО И ЧЕЛОВЕЧЕСКОГО КАПИТАЛА
}

\author{
${ }^{1}$ Мазуркин П.М.
}

ФГБОУ ВПО «Поволжский государственный технологический университет Минобрнауки России», Йошкар-Ола, Россия (424000, Йошкар-Ола, пл. Ленина, 3), e-таil: kaf_po@таil.ru

\begin{abstract}
Показаны устойчивые закономерности динамики эффекта А.Л. Чижевского, влияющего на поведение всего живого на Земле, а также динамики физического и человеческого капитала с 1800 по 2100 годы. Предложены восемь аксиом инноватики. В статье по данным А.Л. Чижевского показана модель среднего эффекта. Поэтому дальнейшими примерами показано, что это эффект является сильно динамичным и по мере роста человечества, по-видимому, ускоряется. Циклы солнечной активности сами изменяются со временем. Из этого эффекта получено следствие: если интенсивность роста в исследуемом историческом процессе больше средней интенсивности по эффекту Чижевского, то этот процесс может быть неустойчивым, кризисным и обладающим значительным риском. Доказано, что к середине XXI века появится третий вид капитала как общечеловеческое достояние по В.И. Вернадскому, то есть ноосферный капитал. Этот капитал общечеловеческой разумности и поведет развитие человечества, резко снижая военные расходы, выставив на первый приоритет планетарную экологическую безопасность.

Ключевые слова: аксиомы инноватики, эффект Чижевского, физический и человеческий капитал, динамика, закономерности, инерционный прогноз
\end{abstract}

\section{DYNAMICS OF PHYSICAL AND HUMAN CAPITAL}

\section{${ }^{1}$ Mazurkin P.M.}

${ }^{1}$ Federal State Educational Institution of Higher Professional Education "Volga State Technological University, Ministry of Education of Russia", Yoshkar-Ola, Russia (424000, Yoshkar-Ola, Lenin square, 3),e-mail:kaf_po@mail.ru

\footnotetext{
Showing consistent patterns of dynamics effect A.L. Chizhevsky affecting the behavior of all life on Earth, as well as the dynamics of the physical and human capital from 1800 to 2100. Proposed eight axioms of innovation. The article according A.L. Chizhevsky shows a model of the average effect. Therefore, examples further show that this effect is highly dynamic and the growth of human, is apparently accelerated. Solar activity cycles themselves change over time. Of this effect is obtained corollary: if the rate of growth in the studied historical process more than the average intensity Chizhevsky effect, this process may be unstable, crisis and with considerable risk. It is proved that by the middle of the twenty-first century will be a third type of capital as a universal property for V.I. Vernadsky, the noosphere is the capital. This capital of universal rationality and lead the development of mankind, dramatically reducing military spending, putting the first priority of the planetary environmental safety.

Key words: axiom of innovation, the effect Chizhevsky, physical and human capital, dynamics, patterns, inertial forecast
}

Введение. Аксиоматические принципы необходимо принять для понимания концепции научно-технического творчества, а также для совершенствования методологии изобретательской деятельности как основного ядра инновационных процессов.

Аксиомы инноватики. В [1] учитываются восемь основополагающих аксиом:

эффект Чижевского (влияние солнечной активности на исторические процессы и на психическую деятельность личности, включая и изобретательскую);

образовательные процессы всеобщи, начиная от момента Большого взрыва и дальнейшего образования Вселенной; 
масса биосферы достоверно постоянна на Земле (по теории биосферы В.И. Вернадского), поэтому энергетический импульс жсизни на планете равен массе биосферы, умноженной на время с момента возникновения планеты (4,6 млрд. лет);

территориальный принцип, известный среди животных и растений, действует (в наше время чаще всего как абстрактная «территория») и среди цивилизованных людей и народов, причем в любой сфере деятельности;

материальное и духовное совместны, они не существуют раздельно, поэтому и в философии нельзя их противопоставлять категорично;

параллельное, а не последовательное развитие формаций человечества, то есть племена первобытных и цивилизации разного уровня экономического, технологического, а ныне и экологического, развития существуют на Земле одновременно;

теоретические и экспериментальные исследования совместны (аналогично фундаментальные и прикладные), поэтому они имеют условное разделение, а безусловное их разделение вредно повлияло на развитие и рост российской науки и техники, причем на практике выполняются вместе (ученный и изобретатель в одном человеке);

изобретает личность, а не коллектив сотрудников, то есть идея приходит в мозг и микрокосмос только отдельного человека, причем в дальнейшем она развивается, уточняется и дорабатывается друзьями, товарищами, коллегами или другими людьми.

Из восьми аксиом далее покажем только первый, так как остальные принципы научнотехнической деятельности были подробно рассмотрены в четырех отчетах по гранту 3.2.3/4603 МОН РФ за 2009-2010 гг.

Эффект Чижевского. Именно этот эффект, хотя и малознакомый в России и полностью преданный забвению в научном сообществе бывшего СССР, оказывает непосредственное влияние на социальную психику, на войны, экономические подъемы и спады, глобальные и локальные кризисы, на появление принципиально новых идей, технических средств и коренных изменений в науке, технике и технологии, экономике.

C середины XX века эффект А.Л. Чижевского стал общепризнанным в мире, причем не только в исторической науке (историометрии).

Историки используют сравнительный метод. По мнению самого А.Л. Чижевского [8, c.5], истинная роль сравнительного метода заключается в обнаружении общности в развитии различных исторических событий и в открытии точных правил этого развития. Главное свойство любой науки - наличие определенных законов, подчиняющих себе явления во всех составляющих их частях.

История есть взаимодействие человека с природой. Исследования английского историка Н.Т. Бокль (1821-1862) А.Л. Чижевский считает началом утверждения о том, что познать за- 
коны истории можно лишь путем статистических наблюдений за деятельностью масс людей, открывающих закономерность массовых поступков. Почти одновременно с Боклем американский химик и историк Д.В. Дрэпер (1811-1882) высказал мысль о том, что историческая эволюция народов управляется естественными законами и находится под влиянием физических агентов природы [8, с.7-8].

В книге [8, с.51] приведены количественные данные среднего историометрического цикла, в котором по годам $t=1,2, \ldots, 11$ приведено количество возникающих исторических событий (также в среднем). После идентификации биотехнического закона [1-5] было получено среднестатистическая модель (рис. 1, табл. 1) в виде уравнения

$$
P=0,00043093 t^{3,77776} \exp \left(-0,0011398 t^{3,56654}\right) .
$$

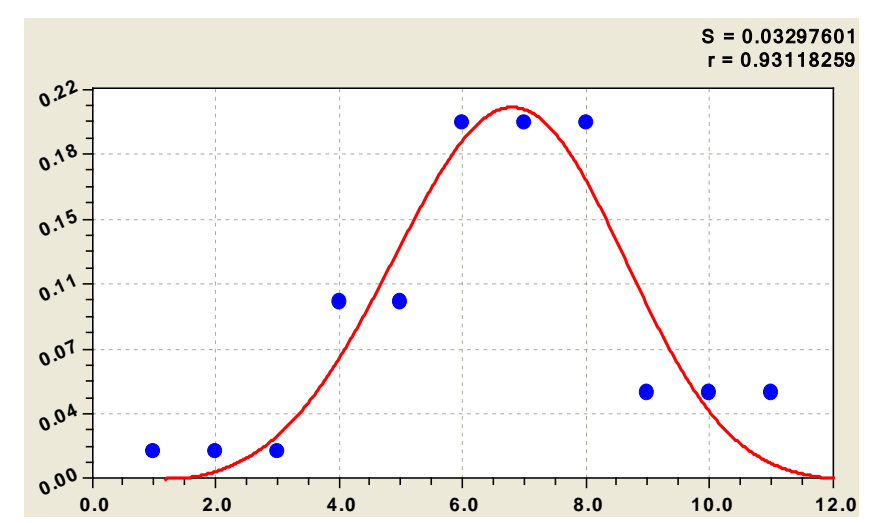

Рис. 1. График цикла солнечной активности по средним данным [8] (в правом верхнем углу приведены: $S$ - сумма квадратов отклонений; $r$ - коэффициент корреляции формулы (1)

грешность всего 3,38 и 4,97\%).

Таблица 1

Вероятность появления исторических событий в среднем цикле солнечной активности (эффект А.Л. Чижевского)

\begin{tabular}{|c|c|c|c|c|}
\hline \multirow{3}{*}{$\begin{array}{l}\text { Время } \\
\text { цикла } \\
t, \text { лет }\end{array}$} & \multirow{3}{*}{$\begin{array}{c}\text { Факт } \\
{[8]} \\
P_{\phi}\end{array}$} & \multicolumn{3}{|c|}{ Тренд по модели (1) } \\
\hline & & расчет & остаток & погрешность \\
\hline & & $P$ & $\varepsilon=P_{\phi}-P$ & $\Delta, \%$ \\
\hline 1 & 0,017 & 0,000430 & 0,016570 & 97,47 \\
\hline 2 & 0,017 & 0,005831 & 0,011169 & 65,70 \\
\hline 3 & 0,017 & 0,025819 & $-0,008819$ & $-51,88$ \\
\hline 4 & 0,100 & 0,069076 & 0,030924 & 30,92 \\
\hline 5 & 0,100 & 0,132095 & $-0,032095$ & $-32,09$ \\
\hline 6 & 0,200 & 0,190058 & 0,009942 & 4,97 \\
\hline 7 & 0,200 & 0,206754 & $-0,006754$ & $-3,38$ \\
\hline 8 & 0,200 & 0,166908 & 0,033092 & 16,55 \\
\hline 9 & 0,050 & 0,096765 & $-0,046765$ & $-93,53$ \\
\hline 10 & 0,050 & 0,038616 & 0,011384 & 22,77 \\
\hline 11 & 0,050 & 0,010095 & 0,039905 & 79,81 \\
\hline
\end{tabular}

Примечания: $P_{\phi}$ - фактические значения вероятности появления исторических событий, $\varepsilon$ - остаток (абсолютная погрешность), $\Delta=100\left(P_{\phi}-P\right) / P_{\phi} \quad$ относительная погрешность модели (1).

тенсивности процесса по средней динамике солнечной активности) изучаемых исторических,

Для графика на рисунке 1 в таблице 1 приведены фактические (по А.Л. Чижевскому [8] в виде точек) и расчетные по (1) динамики появления исторических событий в среднем цикле солнечной активности.

Относительная погрешность среднего цикла высока из-за сильных колебаний числа Вольфа, но она мала при максимуме солнечной активности (относительная по-

При этом и сам цикл меняется по периоду. Поэтому в дальнейшем нужно будет проанализировать все 24 измеренных по числу Вольфа циклов. Это даст возможность прогнозировать поведение разных социумов.

Точные исходные данные по числам Вольфа позволят выделить и волновые колебательные возмущения, например в поведении природных объектов и социумов людей.

Интенсивность роста 3,77776 в формуле (1) по средней солнечной активности по биотехническому закону (1) может быть взята за сравнительную характеристику (критерий ин- 
экологических, экономических, технологических (в том числе и инновационных) и иных явлений и процессов.

Поэтому по числу 3,77776 сформулируем следующее условие: если интенсивность роста в исследуемом историческом процессе больще средней интенсивности по эффекту Чижевского, то этот процесс может быть неустойчивым, кризисным и обладающимм значительным риском. Если же реальный процесс по закону Гуттенберга (19 век) и закону Уилсона (середина ХХ века), количественно выражаемому также биотехническим законом [3-5], имеет интенсивность роста много меньше округленно 3.8, то, как правило (без учета волновой адаптации к поведению всей системы), он является мало интенсивным и не опасным для существования на Земле.

Тогда условие для реальных явлений и процессов получает вид

$$
a_{2} \leq 3,77776 \approx 10\left(1-\Phi^{-1}\right)=10\left(1-1,618033^{-1}\right)=10(1-0,618034)=3,81966,
$$

где $\Phi$ - золотая пропорция, в конкретной статистической модели по биотехническому закону становится критическим уровнем интенсивности роста с момента возникновения изучаемого процесса, который в общем смысле становятся историческим с появлением его описания как события (научного, экологического, технологического, экономического, этнографического, социального, культурного, археологического и др.).

Уравнение (1) можно применять при анализе кризисных и других циклически волновых явлений, зависящих от эффекта Чижсевского [8], т.е. влияния 11-летних циклов на деятельность людей и их сообществ, а также на поведение биологических объектов.

Социально-экономический кризис, начавшийся в России в 1988 году, во многом повторяет 22-й цикл солнечной активности по А.Л. Чижевскому. Конечно же, каждый солнечный цикл имеет свои особенности, однако в среднем за то время, которое учитывалось в исследованиях А.Л. Чижевского, то есть в среднем за последние пять тысяч лет, а также с учетом нескольких циклов вперед, уравнение (1) применимо в экологических, экономических, технологических (инновационных) и иных сравнениях. Из данных таблицы 1 видно, что биотехнический закон (1) может дать модель только для прикидочных расчетов.

Человеческий капитал. В подробной статье [7] приведена методика количественного измерения так называемого человеческого капитала. Понятие человеческого капитала (ЧК) появилось в российской литературе в виде положительной экономической категории и интенсивного фактора развития с переходом к рыночной экономике. До этого публиковались только критические статьи и монографии, объявлявшие теорию человеческого капитала вредной буржуазной теорией, как когда-то кибернетику, генетику и информатику. И поскольку долгие годы экономические кафедры вузов и университетов возглавляли (и возглавляют некоторые до сих пор) профессора с советской ментальностью, то реальное восприятие 
и внедрение в российскую практику теории ЧК затянулось на многие годы. В развитых странах теория и практика ЧК - базовые для разработок концепций, стратегий и программ развития стран и регионов, а также разных организаций.

Существует много определений человеческого капитала, в том числе и основателей теории человеческого капитала Гэри Беккера и Теодора Шульца. Они напрямую связывали понятие ЧК только с человеком, как носителем знаний. И придавали особое значение образованию, как основному фактору развития общества и экономики. В настоящее время такое определение ЧК уже представляется зауженным.

Человеческий капитал включает не только специалистов с образованием, знания, воспитание, науку, но и инструменты интеллектуального труда и среду функционирования специалистов. Действительно, специалист без программного обеспечения его труда, без источников информации, базы данных, методик и технологий не может в современных условиях выполнять свою работу, свои функции. Как и без высокого качества жизни, специалист не будет работать в стране, а уедет туда, где ему обеспечат комфортные условия для труда.

В таблице 2 приведена динамика двух видов капитала [7] и экстремумов физического (максимум) и человеческого (минимум) капитала с начала регистрации (1800 г.).

\section{Изменение структуры совокупного капитала в странах Запада и Японии [7], \%}

\begin{tabular}{|c|c|c|c|c|c|c|c|}
\hline Год & 1800 & 1860 & 1913 & 1950 & 1973 & $1997 / 98$ & Начало 21 в. \\
\hline Время $t$, лет & 0 & 60 & 113 & 150 & 173 & 197 & Прогноз [7] \\
\hline Физический капитал & $78-80$ & $77-79$ & $67-69$ & $52-53$ & $43-44$ & $31-33$ & 20 \\
\hline Максимум & 80 & 79 & 69 & 53 & 44 & 33 & - \\
\hline Человеческий капитал & $20-22$ & $21-23$ & $31-33$ & $47-48$ & $56-57$ & $67-69$ & 80 \\
\hline Минимум & 20 & 21 & 31 & 47 & 56 & 67 & - \\
\hline
\end{tabular}

При низком уровне и качестве человеческого капитала инвестиции в высокотехнологичные отрасли не дают отдачи. Сравнительно быстрые успехи финнов, ирландцев, японцев, китайцев (Тайвань, Гонконг, Сингапур, Китай и др.), корейцев, новых европейских развитых стран (Греция, Испания, Португалия) подтверждают вывод о том, что фундаментом для формирования человеческого капитала является высокая культура и менталитет.

Динамика максимума физического каптала $K$ (рис. 2) имеет формулу

$$
K=79,99955 \exp \left(-0.0077335 t^{1,13645}\right)+0,21751 t^{1,40831} \exp \left(-0,0014293 t^{1,41480}\right) .
$$

Первая составляющая является естественной тенденцией, мало зависящей от людей, а вторая составляющая показывает, как правило, антропогенное воздействие. Коэффициент корреляции 0,9998 показывает высокую адекватность модели (3). По ней в Ехсеl была определена максимальная относительная погрешность $100 \times 0.72$ / $44=1,64 \%$. Такая погрешность меньше даже по сравнению с техническими экспериментами (менее 5\%). 
Пик колебания мирового физического капитала был в 1973 г.. Однако, для волновых составляющих нужны ежегодные данные.

Человеческий капитал является самостоятельным экономическим ресурсом, собственно, фундаментом роста ВВП в сочетании с НТП

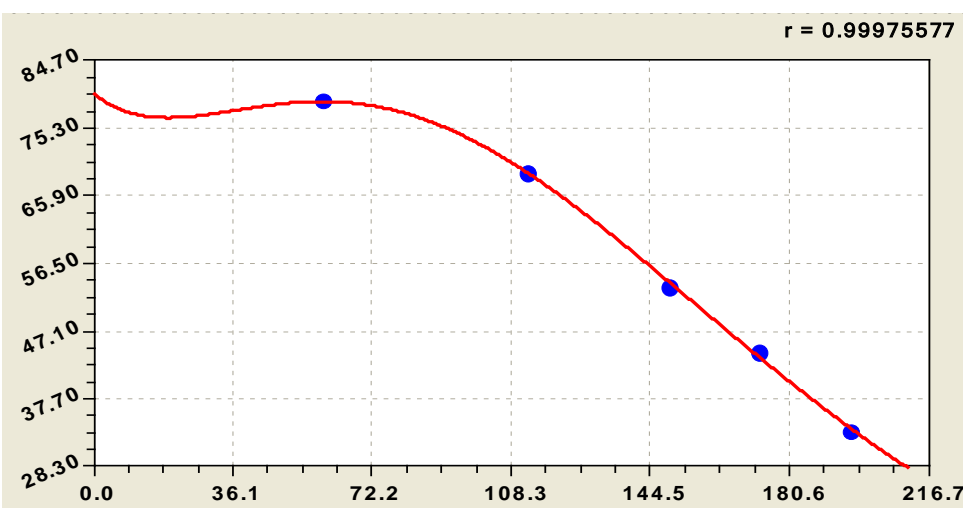

Рис. 2. Динамика физического капитала мира с 1800 по 1997 гг. в современных условиях. Отличие его от природных ресурсов, классического труда и обычного капитала состоит в необходимости постоянных повышенных инвестиций в него и существование значительного временного лага в отдаче от этих инвестиционных вложений.

В развитых странах мира в конце 1990-х годов в человеческий капитал вкладывалось около 70\% всех средств, а в физический капитал - только около $30 \%$ (табл. 2). Основную долю инвестиций в человеческий капитал в передовых странах осуществляет государство. Это важнейшая функция государственного регулирования экономики.

Динамика минимума человеческого капитала (рис. 3) получила биотехническую закономерность по аналогичной конструкции формулы

$$
\Psi=20,02244 \exp \left(-1.32906 \cdot 10^{-5} t^{1,57079}\right)+6,23842 \cdot 10^{-10} t^{5,47166} \exp \left(-0,019594 t^{0,99928}\right) .
$$

Первая естественная составляющая снова показывает спад по экспоненциальному закону. Этот факт, хотя он по расчетам незаметный (табл. 3), указывает на то, что без эффективной национальной системы воспитания и образования человеческий капитал медленно вымирает.

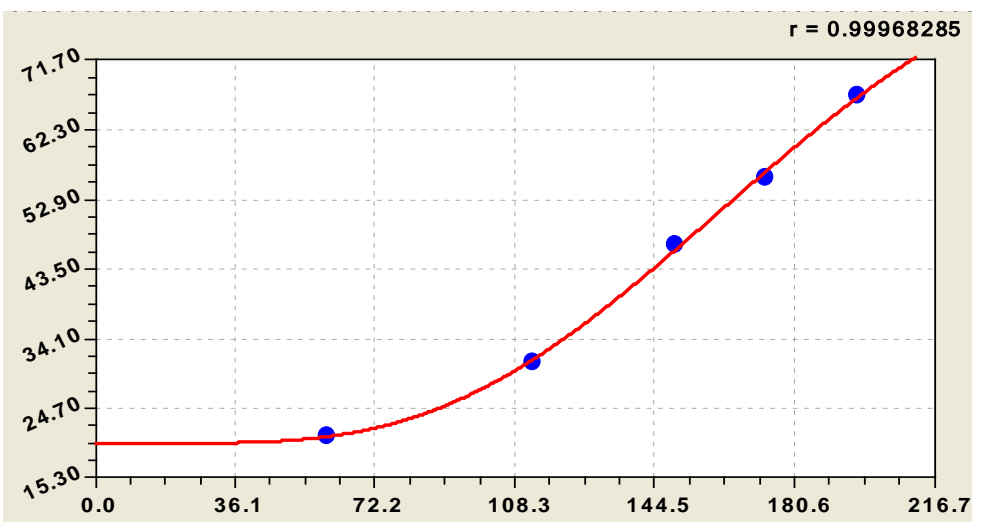

Рис. 3. Динамика человеческого капитала мира с 1800 по 1997 гг.
Вторая составляющая позитивного стрессового возбуждения показывает предел роста (по Медоуз), который по расчетам достигнет примерно 64,67\% к 2080 году.

При почти неизменной первой составляющей максимум общего человеческого капитала будет равным 84,89\% или примерно 85\% в мире составит человеческий капитал, а всего 15\% - физический капитал.

Максимальная относительная погрешность (3) равна $100 \times 1.54 / 56=2,74 \%$. После 2080 года по (4) ожидается начало спада и этот факт указывает, что физический и человеческий капитал имеют циклически-волновой характер изменения. При этом с 2040 года сумма физического и человеческого каптала становится меньше $100 \%$. 
Изменение структуры совокупного капитала в странах Запада и Японии, \%

\begin{tabular}{|c|c|c|c|c|c|c|c|c|c|c|c|c|c|}
\hline \multirow{3}{*}{ Годы } & \multirow{3}{*}{$\mid \begin{array}{c}\text { Время } \\
t, \text { лет }\end{array}$} & \multicolumn{6}{|c|}{ Физический капитал } & \multicolumn{6}{|c|}{ Человеческий капитал } \\
\hline & & \multirow{2}{*}{$K_{\phi}$} & \multicolumn{3}{|c|}{ расчетный } & \multirow[b]{2}{*}{$\varepsilon$} & \multirow[b]{2}{*}{$\Delta, \%$} & \multirow[b]{2}{*}{$\Psi_{\phi}$} & \multicolumn{3}{|c|}{ расчетный } & \multirow[b]{2}{*}{$\varepsilon$} & \multirow{2}{*}{$\Delta, \%$} \\
\hline & & & $K_{1}$ & $K_{2}$ & K & & & & $\Psi_{1}$ & $\Psi_{2}$ & 4 & & \\
\hline \multicolumn{14}{|c|}{ Основание прогноза } \\
\hline 1800 & 0 & 80 & 80,00 & 0,00 & 80,00 & 0,00 & 0,00 & 20 & 20,02 & 0,00 & 20,02 & $-0,02$ & $-0,11$ \\
\hline 1860 & 60 & 79 & 35,54 & 43,46 & 79,01 & $-0,01$ & $-0,01$ & 21 & 20,02 & 1,04 & 21,06 & $-0,06$ & $-0,28$ \\
\hline 1913 & 113 & 69 & 15,12 & 53,76 & 68,88 & 0,12 & 0,17 & 31 & 20,02 & 11,76 & 31,79 & $-0,79$ & $-2,53$ \\
\hline 1950 & 150 & 53 & 8,03 & 45,50 & 53,53 & $-0,53$ & $-1,00$ & 47 & 20,02 & 26,92 & 46,94 & 0,06 & 0,12 \\
\hline 1973 & 173 & 44 & 5,36 & 37,91 & 43,28 & 0,72 & 1,64 & 56 & 20,02 & 37,51 & 57,54 & $-1,54$ & $-2,74$ \\
\hline 1997 & 197 & 33 & 3,49 & 29,82 & 33,31 & $-0,31$ & $-0,94$ & 67 & 20,02 & 47,82 & 67,84 & $-0,84$ & $-1,25$ \\
\hline \multicolumn{14}{|c|}{ Горизонт прогноза } \\
\hline $2000 *$ & 200 & - & 3,30 & 28,85 & 32,15 & - & - & - & 20,02 & 48,99 & 69,01 & - & - \\
\hline $2010^{*}$ & 210 & - & 2,75 & 25,71 & 28,46 & - & - & - & 20,02 & 52,64 & 72,66 & - & - \\
\hline 2015 & 215 & - & 2,51 & 24,21 & 26,72 & - & - & - & 20,02 & 54,31 & 74,33 & - & - \\
\hline 2020 & 220 & - & 2,29 & 22,75 & 25,05 & - & - & - & 20,02 & 55,87 & 75,89 & - & - \\
\hline 2025 & 225 & - & 2,09 & 21,35 & 23,45 & - & - & - & 20,02 & 57,31 & 77,33 & - & - \\
\hline 2030 & 230 & - & 1,91 & 20,01 & 21,92 & - & - & - & 20,02 & 58,63 & 78,65 & - & - \\
\hline 2050 & 250 & - & 1,32 & 15,19 & 16,51 & - & - & - & 20,02 & 62,64 & 82,66 & - & - \\
\hline 2080 & 280 & - & 0,75 & 9,65 & 10,39 & - & - & - & 20,02 & 64,87 & 84,89 & - & - \\
\hline 2100 & 300 & - & 0,51 & 6,95 & 7,46 & - & - & - & 20,02 & 64,07 & 84,09 & - & - \\
\hline
\end{tabular}

Примечания. *Для сравнения с фактическими данными. Прогноз [7] (физический капитал 20\% и человеческий капитал 80\%) в мире будет достигнут только к 2035 году.

Это означает только одно: к середине XXI века появится третий вид капитала и мы полагаем, что это будет общечеловеческое достояние по В.И. Вернадскому, то есть ноосферный капитал. Этот капитал общечеловеческой разумности и поведет развитие человечества, снижая военные расходы, приняв за первичность планетарную экологическую безопасность.

Американцы это поняли более 40 лет назад, и внимание сосредоточили на климатические и экологические технологии на Земле и космические технологии в Солнечной системе.

Постоянство первого члена по данным таблицы 3 на уровне 20,02\% позволяет редуцировать формулу (4) на XXI век в уравнение вида

$$
\Psi=20,02244+6,23842 \cdot 10^{-10} t^{5,47166} \exp \left(-0,019594 t^{0,99928}\right) .
$$

Пик колебания человеческого капитала также был в 1973 г. (рис. 4).

Этот пик колебания характеризуется асимметричным вейвлет-сигналом по третьей составляющей к (5) в виде

$$
\Psi_{3}=A \cos (\pi t / p+1,00883),(6)
$$

$A=-1,38526 \cdot 10^{-8} t^{4,12662} \exp (-0,014349 t)$,

$$
p=20,88138+0,0032628 t,
$$

где $A$ - амплитуда (половина) колеба-

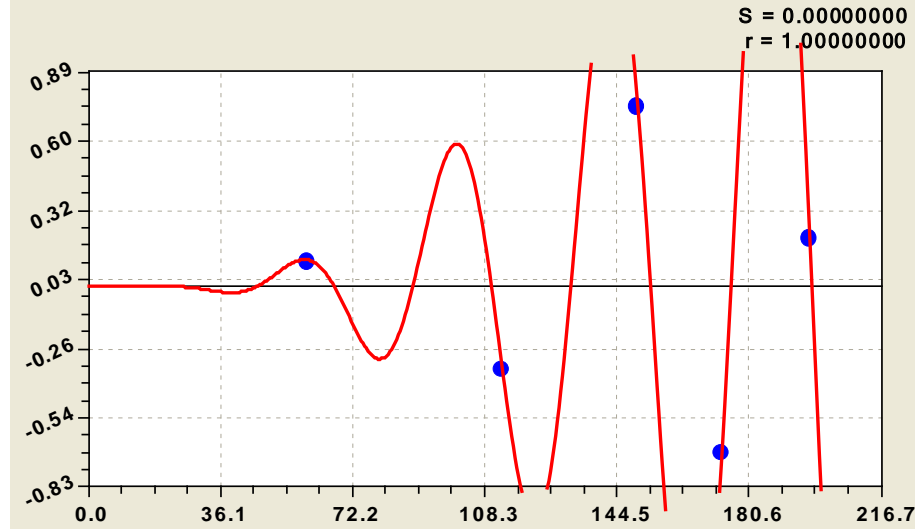

Рис. 4. Волновая динамика человеческого капитала мира с 1800 по 1997 гг. ния человеческого капитала, \%, $p$ - полупериод волны колебательного возмущения, лет. 
Вывод. Для точного анализа новых видов капитала нужны ежегодные данные, а управление инновационной деятельностью в России должна проводиться при ежегодном мониторинге человеческого и физического капитала, а также глобального инновационного индекса. Список литературы

1. Мазуркин П.М. Основы научных исследований: учеб. пос. Йошкар-Ола: МарГТУ, 2006. 412c. 2. Мазуркин П.М. Функциональное проектирование систем машин // Проблемы формирования систем машин и техники новых поколений: сб. статей. Том 1. Часть 1. М.: ВНИИПМ, 1990. С.106-121.

3. Мазуркин П.М., Сабанцев Ю.Н. Инновационный и воспроизводственный циклы в машиностроении // Теория предвидения и будущее России: матер. V Кондратьевских чтений. М.: Ин-т экономики РАН, 1997. С. 266-272.

4. Мазуркин П.М., Сабанцев Ю.Н. Инновационный и воспроизводственный циклы в машиностроении // Теория предвидения и будущее России: матер. V Кондратьевских чтений. М.: Ин-т экономики РАН, 1997. С. 266-272.

5. Мазуркин П.М., Сабанцев Ю.Н. Кондратьевские циклы в лесной экономике // Теория предвидения и будущее России: матер. V Кондратьевских чтений. М.: Институт экономики PAH, 1997. C. 242-247.

6. Розин B.M. Философия техники: Учеб. пос. М.: NOTA BENE, 2001. 456 с.

7. Эффективность национального человеческого капитала: методика измерения. URL: http://www.lerc.ru/?part=articles\&art=1\&page=119 (дата обращения 15.10.2013).

8. Чижевский А.Л. Физические факторы исторического процесса. Калуга: 1-я Гостиполитография, 1924. $72 \mathrm{c.}$

The list of references

1. Mazurkin P.M. Bases of scientific researches: manual Yoshkar-Ola: Mari State Technical University, 2006. $412 \mathrm{p}$.

2. Mazurkin P.M. Functional design of systems of cars // Problems of formation of systems of cars and equipment of new generations: collection of articles. Volume 1. Part 1. M: Voronezh Research Institute of Semiconductor Mechanical Engineering, 1990. P. 106-121.

3. Mazurkin P.M., Sabantsev Y.N. Innovative and reproduction cycles in mechanical engineering // the Theory of anticipation and the future of Russia: materials V of Kondratyevsky readings. Moscow: Institute of economy of the Russian Academy of Sciences, 1997. P. 266-272.

4. Mazurkin P.M., Sabantsev Y.N. Innovative and reproduction cycles in mechanical engineering//the Theory of anticipation and the future of Russia: materials V Kondratyevsky readings. Moscow: Institute of economy of the Russian Academy of Sciences, 1997. P. 266-272.

5. Mazurkin P.M., Sabantsev Y.N. Kondratyevsky cycles in forest economy // the Theory of anticipation and the future of Russia: materials V of Kondratyevsky readings. Moscow: Institute of economy of the Russian Academy of Sciences, 1997. P. 242-247.

6. Rozin V.M. Equipment philosophy: Educational manual Moscow: NOTA BENE, 2001. 456 p.

7. Efficiency of the national human capital: measurement technique. URL: http://www.lerc.ru/?part=articles\&art=1\&page=119 (date of the address 15.10.2013).

8. Chizhevsky A.L. Physical factors of historical process. Kaluga: 1st Gostipolitografiya, 1924. 72 p.

Рецензенты: ФИО, ученая степень, звание, должность, место работы, город.

Салихов Мухаммет Габдулхаевич, доктор технических наук, профессор, академик РАЕ, почетный работник ВПО РФ, заслуженный деятель науки РМЭ, заведующий кафедрой автомобильных дорог ФГБОУ ВПО «Поволжский государственный технологический университет», 424000. г. Йошкар-Ола, пл. Ленина, 3. Тел. (8362)68-60-72.

Колупаев Борис Иванович, доктор биологических наук, профессор, профессор кафедры водных ресурсов ФГБОУ ВПО «Поволжский государственный технологический университет», 424000. г. Йошкар-Ола, пл. Ленина, 3. Тел. (8362)68-68-58. 